\title{
Early-stage mucinous sweat gland adenocarcinoma of eyelid
}

This article was published in the following Dove Press journal:

Clinical Ophthalmology

20 May 2011

Number of times this article has been viewed

\section{Tomohiro Nizawa' \\ Toshiyuki Oshitari' \\ Ryuta Kimoto' \\ Fusae Kajita' \\ Jiro Yotsukura' \\ Kaoru Asanagi' \\ Takayuki Baba' \\ Yoko Takahashi \\ Takashi Oide ${ }^{2}$ \\ Takako Kiyokawa ${ }^{2}$ \\ Takashi Kishimoto ${ }^{2}$ \\ Shuichi Yamamoto' \\ 'Department of Ophthalmology and Visual Science, ${ }^{2}$ Department of \\ Molecular Pathology, Chiba University \\ Graduate School of Medicine, \\ Chuo-ku, Chiba, Japan}

Correspondence: Toshiyuki Oshitari Department of Ophthalmology and Visual Science, Chiba University Graduate School of Medicine, Inohana I-8-I, Chuo-ku, Chiba 260-8670, Chiba, Japan

$\mathrm{Tel}+8 \mathrm{I} 432262124$

Fax+8I 432244162

Email tarii@aol.com

\begin{abstract}
We present the findings of an early-stage primary mucinous sweat gland adenocarcinoma in the lower eyelid of a Japanese patient. The patient was a 73-year-old man who had had a nodule on the left lower eyelid for two years. He was referred to our hospital with a diagnosis of a swollen chalazion. The clinical and histopathological records were reviewed and the mass was excised. Histopathological examination revealed a mucinous sweat gland adenocarcinoma. Postoperative magnetic resonance imaging and positron emission tomography excluded systemic metastases. After the histopathological findings, a complete surgical excision of the margins of the adenocarcinoma was performed, with histopathological confirmation of negative margins. After the final histopathological examination, the patient was diagnosed with a primary mucinous sweat gland adenocarcinoma of the left eyelid. Six months after the surgery, no recurrence has been observed. Because the appearance of mucinous sweat gland adenocarcinoma of the eyelid is quite variable, the final diagnosis can only be made by histopathological examination. A complete surgical excision is recommended.
\end{abstract}

Keywords: complete surgical excision, eyelid, initial stage, mucinous sweat gland adenocarcinoma

\section{Introduction}

Primary mucinous sweat gland adenocarcinoma of the eyelid is very rare in Japan. ${ }^{1}$ A search of PubMed yielded 25 articles describing 55 patients with mucinous sweat gland adenocarcinoma of the eyelid. ${ }^{1}$ Of the 55 patients, only two Asian cases $(5.7 \%)$ were reported, ${ }^{1}$ and $28(50.9 \%)$ were Caucasians. ${ }^{1}$ We present the findings in a Japanese patient with primary mucinous sweat gland adenocarcinoma of the left lower eyelid at an early stage and discuss the progression pattern of this adenocarcinoma.

\section{Case report}

A 73-year-old man noticed a swelling of the left lower eyelid two years earlier. Because the size of the nodule gradually increased, the patient was referred to Chiba University Hospital for evaluation. He had systemic hypertension but no family history of any ocular diseases. At 69 years of age, he had undergone polypectomy for colonic cancer.

At our first examination, an $8 \mathrm{~mm} \times 10 \mathrm{~mm}$ painless, mobile nodule was palpable in the left eyelid. The mass resembled a benign granuloma or chalazion (Figure 1A).

We performed nodule excision with clinically visible margins. The tentative diagnosis during the operation was a hemangioma and not a chalazion or benign granuloma. The nodule was horizontally extended and attached to the tarsal plate. 
A

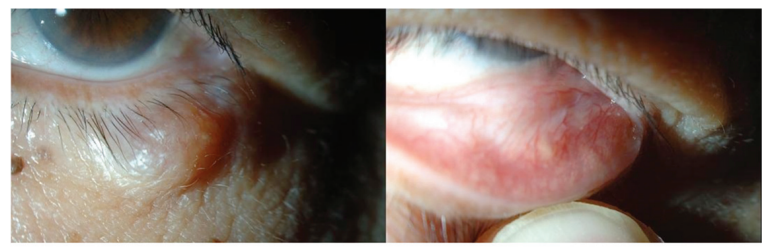

B

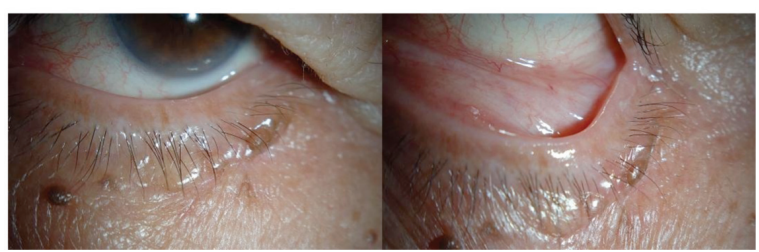

Figure I Preoperative clinical appearance of the left lower eyelid mass (A) and postoperative clinical appearance of the left lower eyelid lesion (B). The mass was painless and mobile (A) and no recurrence had occurred six months after complete excision surgery $(\mathbf{B})$.

Histopathology revealed floating clumps of cuboidal cells with focal duct formation in the abundant mucin lakes (Figure 2). Postoperative magnetic resonance imaging and positron emission tomography scanning excluded systemic tumors. Thus, the final diagnosis of his tumor was a primary mucinous sweat gland adenocarcinoma of the left lower eyelid. Because of the histopathological diagnosis, we performed a second operation to excise the margins of the tumor until the tissue was histologically confirmed to be negative. Six months after the second operation, no recurrence or metastasis was found (Figure 1B).

\section{Discussion}

The prevalence of mucinous sweat gland adenocarcinoma of the eyelid seems to be lower in Asians than in the Caucasian population. ${ }^{1}$ In many cases, the initial diagnosis was that the mass was benign, as in our case. ${ }^{1,2}$ Zhang et al reported six cases of mucinous eccrine adenocarcinoma of the eyelid. ${ }^{2}$ The initial clinical diagnosis in the different cases was papilloma, neoplasm, chalazion, pyogenic granuloma, hemangioma, and basal cell carcinoma. ${ }^{2}$ Thus, the clinical appearance of mucinous sweat gland carcinoma of the eyelid is very variable.

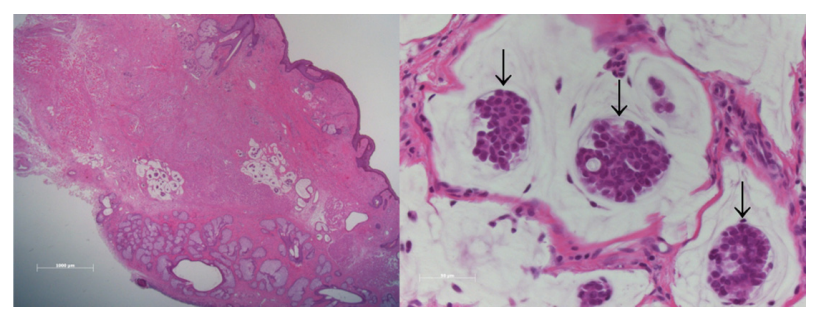

Figure 2 Histopathological findings from the specimen. Floating clumps of cuboidal cells with focal duct formation in the abundant mucin lakes (arrows) indicate a sweat gland adenocarcinoma.
Mucinous sweat gland adenocarcinoma of the eyelid arises from an eccrine gland or apocrine gland. ${ }^{2}$ Histologically, the tumor in our patient was composed of floating clumps of carcinoma cells in a sea of mucin, but we could not determine the precise origin in our case. It is unlikely that the adenocarcinoma in our patient was a metastasis of colonic cancer from the histology suggesting mucinous sweat gland adenocarcinoma and positron emission tomography findings indicating no recurrence of colonic cancer or systemic metastasis.

The progression pattern at the early stage of mucinous sweat gland adenocarcinoma of the eyelid is shown in Figure 3. In general, a sebaceous carcinoma is vertically extended in the eyelid at the initial stage. Thus, in many cases, the progression pattern could be differentiated from benign disorders, such as chalazion. However, a mucinous sweat gland adenocarcinoma is present on the surface of the eyelid and extends horizontally slowly onto the tarsal plate (Figure 3). Thus, the mucinous sweat gland adenocarcinoma of the eyelid is extremely difficult to differentiate from a malignant tumor at the initial stage. In some cases, malignant should probably be changed for benign. In fact, some patients have had a recurrence of tumor at the excised region, which was reported to be benign. ${ }^{3-5}$

In summary, we have reported a Japanese case of primary mucinous sweat gland adenocarcinoma of the eyelid. Because of the difficulties in differentiating it from benign disorders, histopathological examination should be performed. A complete excision with histological confirmation of negative surgical margins of resection is required to reduce the chances of a recurrence.

\section{Acknowledgments}

This study was supported by the Grant-in-Aid for Scientific Research from Ministry of Education, Science, Sports, and Culture in Japan. We wish to thank Professor Duco Hamasaki of the Bascom Palmer Eye Institute of the University of Miami for editing this manuscript.
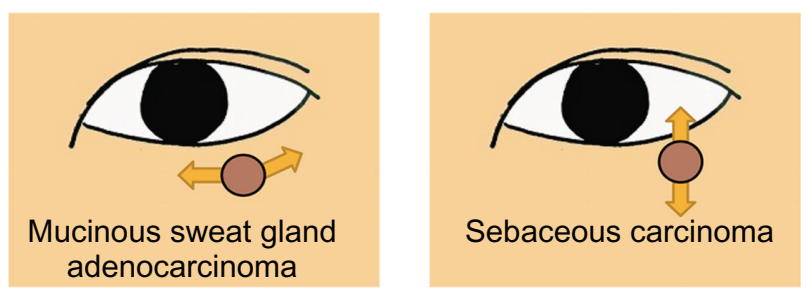

Figure 3 Scheme for the progression pattern of the sweat gland adenocarcinoma compared with sebaceous carcinoma of the eyelid. In general, a sebaceous carcinoma is vertically extended in the eyelid at the initial stage. However, the mucinous sweat gland adenocarcinoma is present on the surface of the eyelid and extends horizontally slowly onto the tarsal plate. 


\section{Disclosure}

The authors report no conflicts of interest in this work.

\section{References}

1. Segal A, Segal N, Gal A, Tumuluri K. Mucinous sweat gland adenocarcinoma of the eyelid - current knowledge of a rare tumor. Orbit. 2010;29:334-340.

2. Zhang Q, Wojno TH, Fitch SD, Grossniklaus HE. Mucinous eccrine adenocarcinoma of the eyelid: Report of 6 cases. Can J Ophthalmol. 2010;45:76-78.
3. Chauhan A, Ganguly M, Takkar P, Dutta V. Primary mucinous carcinoma of eyelid: A rare clinical entity. Indian J Ophthalmol. 2009;57: $150-152$.

4. Durairaj VD, Hink EM, Kahook MY, Hawes MJ, Paniker PU, Esmaeli B. Mucinous eccrine adenocarcinoma of the periocular region. Ophthal Plast Reconstr Surg. 2006;22:30-35.

5. Cabell CE, Helm KF, Sakol PJ, Billingsley EM. Primary mucinous carcinoma in a 54-year-old man. J Am Acad Dermatol. 2003;49:941-943.
Clinical Ophthalmology

\section{Publish your work in this journal}

Clinical Ophthalmology is an international, peer-reviewed journal covering all subspecialties within ophthalmology. Key topics include: Optometry; Visual science; Pharmacology and drug therapy in eye diseases; Basic Sciences; Primary and Secondary eye care; Patien Safety and Quality of Care Improvements. This journal is indexed on

Submit your manuscript here: http://www.dovepress.com/clinical-ophthalmology-journal

\section{Dovepress}

PubMed Central and CAS, and is the official journal of The Society of Clinical Ophthalmology (SCO). The manuscript management system is completely online and includes a very quick and fair peer-review system, which is all easy to use. Visit http://www.dovepress.com/ testimonials.php to read real quotes from published authors. 